IOS Press

\title{
When is administrative data good enough to replace statistical information? A quality indicator based on census comparison
}

\author{
Sandra Lagarto*, Anabela Delgado, Paula Paulino and João Capelo \\ Statistics Portugal, Lisbon, Portugal
}

\begin{abstract}
Statistics Portugal is considering the use of administrative data in the 2021 Census. To face this challenge, the quality of the available administrative data is measured comparing administrative data with census microdata. The goal is to evaluate the risks of replacing part of the census collected information with information obtained from administrative sources. Record linkage methods were applied and fifteen variables from seven administrative datasets (namely Social Security or Students register) were selected based on the potential for replace census collected information. For each matched record pair, information from corresponding administrative variables is compared, producing an equality rate estimate. The results show very high equality rates when comparing information from each matched pair of records to both geographical and demographic variables (municipality of residence, sex, date of birth, legal marital status, country of birth, country of citizenship). When comparing socioeconomic variables, results are less homogeneous (nevertheless, data obtained by sources related with labour force, also got high correspondence rates for compared record pairs). Considering that some statistics might be obtained by other sources, some Census microdata (regarding economic and educational characteristics of the population) were compared with data from the national Labour Force Survey. These results converge to the general comparison results of this exercise. Finally, the results of the Post Enumeration Survey of the 2011 Census were used to verify the reliability of the comparison results.
\end{abstract}

Keywords: 2021 Portugal Population and Housing Census, administrative data, census microdata, linked data

\section{Background}

The Portuguese strategy for the 2021 Census considers the use of administrative data to provide information on some specific census topics, following the EU and UNECE countries' general trend regarding a more efficient census method, with high quality standards, but less burdensome for the respondents and less costly for the State. Statistics Portugal (INE) is currently conducting a feasibility study for the 2021 Population and Housing Censuses' new model which evaluates the usability of available administrative data for statistical purposes.

One of the steps of that study is to compare the char-

*Corresponding author: Sandra Lagarto, Instituto Nacional de Estatística, Gabinete para os Censos 2021, Av. António José de Almeida, 1000-043 Lisboa. E-mail: sandra.lagarto@ine.pt. acteristics of a set of register-based population with the corresponding characteristics from national results of the 2011 Population Census. This exercise will show how administrative data collected by several sources approximates to the census collected data and point out discrepancies.

To support the obtained results from some economical and educational characteristics of the population, we also compare microdata from the 2011 Census to the Portuguese Labour Force Survey (LFS) from the 1st quarter of 2011. Also, we use 2011 Census Consistency Index (ICG), from the Post Enumeration Survey (PES), to validate results.

\section{Selection of administrative sources and variables for census purposes}

Considering the feasibility study for the 2021 Cen- 
Table 1

Administrative datasets sources to compare with the 2011 Census microdata

\begin{tabular}{|c|c|c|c|c|}
\hline Administrative sources & Year & No. records & Description & Name \\
\hline Institute of registration and notary & 2010 & 11565714 & Civil register & BDIC \\
\hline Immigration and borders service & 2011 & 434708 & Foreigner register & SEF \\
\hline Social security institution & 2011 & 7209027 & Social Security register & ISS \\
\hline Strategy and planning office & 2011 & 2736659 & $\begin{array}{l}\text { Private employment register } \\
\text { (Bulletin of Labour and Employment) }\end{array}$ & QP \\
\hline $\begin{array}{l}\text { Institute of employment and training } \\
\text { and regional directorate of statistics of Madeira }\end{array}$ & 2011 & 702215 & Unemployment register & IEFP \\
\hline $\begin{array}{l}\text { General directorate of education and science } \\
\text { statistics and regional secretariat for education and } \\
\text { human resources of the autonomous region of Madeira }\end{array}$ & 2011 & 1965842 & Students register & EDUC \\
\hline General Retirement Fund & 2010 & 1103980 & Public administration retirement fund register & CGA \\
\hline
\end{tabular}

Table 2

Selected administrative topics to compare with 2011 Census variables

\begin{tabular}{ll}
\hline $\begin{array}{l}\text { Administrative } \\
\text { dataset }\end{array}$ & Available information on population topics \\
\hline BDIC & $\begin{array}{l}\text { Place of residence (municipality), sex, date of } \\
\text { birth, legal marital status, country of birth, } \\
\text { country of citizenship } \\
\text { Country of birth, country of citizenship, current } \\
\text { activity status, occupation }\end{array}$ \\
SEF & $\begin{array}{l}\text { Current activity status, place of work, status in } \\
\text { employment }\end{array}$ \\
ISS & $\begin{array}{l}\text { Place of work, occupation, industry (establish- } \\
\text { ment), status in employment, number of per- }\end{array}$ \\
QP & sons working in the enterprise, \\
& hours usually worked, educational attainment \\
& Current activity status \\
Current activity status
\end{tabular}

sus, the legal frame which allowed Statistics Portugal the access to administrative data was established by the Law no. 22/2008 on the National Statistical System of 13.05.2008 and the Deliberation of the National Commission for Data Protection no. 929/2014 of 11.06.2014 (numeric identifiers were encrypted and no full access to both names and addresses were allowed).

For the current exercise, 9 data sources were selected considering the potential use of administrative data for census information (see Table 1). In the selected administrative data sources, 15 target variables formerly provided by 2011 national Census were identified: 7 concerning geographical and demographic characteristics and 8 concerning economical and educational characteristics (see Table 2).

\section{Methodological aspects}

The aim of this exercise is to compare, for each person, the exact value of the target variable on administrative datasets, which is the closest as possible with the statistical concept and definition, with the 2011 Census microdata.

The population in comparison results from a previous match-key process between the 2011 Census microdata and the administrative records, selected from the several sources in a stepwise manner (using combinations of available information - sex/name/date of birth/marital status/country of citizenship/municipality of usual residence - to link census microdata to each administrative datasets, sequentially). Data preparation (including recoding) and standardization were previously performed. There were no missing characteristics added to the registers and data was considered up to date.

It was possible to match 9949599 census records to administrative records from selected sources, which means 94 per cent of the resident population stock back in 2011, with a false positive rate of 6 per cent (that value represents the total number of matched census records with at least one administrative dataset).

Considering the matched records, the main purpose of this exercise is to evaluate, for a selection of variables, if we get the same information from administrative datasets on individuals as the one collected in the 2011 Census. Only after the analysis of these results we could consider the use of administrative data to replace census collected statistics information.

The equality rate was estimated based on the comparison of exact information on each pairs of records that were possible to match. For those records, which represent the same person, our hypothesis is that, if equality is verified, we can rely on administrative information for statistical purposes. To support this decision, we have two additional criteria: results from the 2011 Census Post Enumeration Survey ICG and also results from the comparison between the 2011 Census and 2011 first quarter Labour Force Survey microdata. 
Table 3

2011 Census microdata and administrative records comparison results

\begin{tabular}{|c|c|c|c|c|c|c|}
\hline \multirow{2}{*}{$\begin{array}{l}\text { Variable } \\
\text { Place of residence (municipality) }\end{array}$} & \multirow{2}{*}{$\begin{array}{r}2011 \text { Census } \\
\text { population to } \\
\text { be compared }\end{array}$} & \multicolumn{2}{|c|}{$\begin{array}{l}\text { Administrative } \\
\text { records to be } \\
\text { compared, by source }\end{array}$} & \multirow{2}{*}{$\begin{array}{r}\begin{array}{r}\text { Number } \\
\text { of pairs } \\
\text { compared }\end{array} \\
9308384\end{array}$} & \multirow{2}{*}{$\begin{array}{l}\text { Equality } \\
\text { rate }(\%) \\
94.6\end{array}$} & \multirow{2}{*}{$\begin{array}{r}\mathrm{ICG}^{3} \\
(\%) \\
97.7\end{array}$} \\
\hline & & BDIC & 11565714 & & & \\
\hline Sex & 10562178 & BDIC & 11565714 & 9308384 & 99.9 & 99.0 \\
\hline Date of birth & 10562178 & BDIC & 11565714 & 9308384 & 92.6 & 95.7 \\
\hline Legal marital status & 10562178 & BDIC & 11565714 & 9308384 & 95.3 & 97.4 \\
\hline \multirow[t]{2}{*}{ Country of birth } & 10562178 & BDIC & 11565714 & 9308384 & 94.7 & 84.0 \\
\hline & & SEF & 434708 & 107136 & 91.3 & 84.0 \\
\hline \multirow[t]{2}{*}{ Country of citizenship } & 10562178 & BDIC & 11565714 & 9308384 & 99.4 & 97.8 \\
\hline & & SEF & 434708 & 107136 & 90.3 & 97.8 \\
\hline \multirow[t]{4}{*}{ Current activity status } & 8989849 & ISS & 7066838 & 4910073 & 81.2 & \\
\hline & & SEF & 379965 & 107136 & 27.1 & \\
\hline & & CGA & 1103980 & 716264 & 92.1 & \\
\hline & & IEFP & 702215 & 454479 & 42.1 & \\
\hline \multirow[t]{2}{*}{ Place of work (municipality) } & 4361187 & ISS & 4107425 & 2788758 & 56.6 & 77.6 \\
\hline & & QP & 2736659 & 2045476 & 81.6 & 77.6 \\
\hline \multirow[t]{2}{*}{ Occupation } & 4361187 & QP & 2736659 & 2045476 & 61.9 & \\
\hline & & SEF & 124721 & 171370 & 52.9 & \\
\hline Industry & 4361187 & QP & 2736659 & 2045476 & 74.1 & \\
\hline \multirow[t]{2}{*}{ Status in employment } & 4361187 & QP & 2736659 & 2045476 & 93.0 & 82.2 \\
\hline & & ISS & 4107425 & 2788758 & 85.5 & 82.2 \\
\hline Number of persons working in the enterprise & 4361187 & $\mathrm{QP}$ & 2736659 & 2045476 & 54.4 & 51.6 \\
\hline Hours usually worked & 4361187 & QP & 2736659 & 2045476 & 56.8 & \\
\hline Educational attainment & 10445093 & QP & 2736659 & 2210930 & 59.5 & \\
\hline School attendance & 10445093 & EDUC & 1965842 & 1359916 & 82.2 & 69.8 \\
\hline
\end{tabular}

\section{Results and discussion}

Table 3 summarizes the obtained results from the comparison exercise, for the set of selected census variables with available administrative information to compare with. We show the population numbers, the number of available administrative records and the actual number of administrative records compared to census microdata (resulted from matching process). We also present the values of the Global Consistency Index (ICG) from the Post Enumeration Survey (PES) of the 2011 Census [1].

Before presenting the results, two notes: one to categorical variables and another one to variables with different detailed levels of information. In this paper, we only show results for all categories and aggregated information, but the study carried out was exhaustive and detailed in comparisons, producing a vast set of results.

The first note is to enhance that all categorical variables were also compared by groups. If we take, for instance, current activity status, the equality rate point in Table 3 is about 81 per cent when we compare cen-

\footnotetext{
${ }^{1}$ ICG measures content errors; it represents the percentage of statistical units (resident population), with the same classification both in the 2011 Census and 2011 Census PES, of all common units to the two statistical operations.
}

sus microdata to individual social security (ISS) registers for all categories. In this case, within groups, comparisons may have some variations. Considering again current activity status, 92 per cent of those who respond in census questionnaire that were employed are registered in the Portuguese Social Security system as employed.

The second note is to consider variables with different levels of information. If we take occupation, for instance, Table 3 points to about 62 per cent of equality rate when census microdata is compared to individual private employment $(\mathrm{QP})$ registers. That value corresponds to the highest aggregation level of information, that is to say, one-digit level. The general trend, for this type of variables, is that the higher the disaggregation, the lower the equality rate estimated.

Let's now analyse the global exercise comparison results on Table 3. The comparison results on demographic variables show high equality rates -90 to 99 per cent - on date of birth, sex, country of birth, country of citizenship and legal marital status. Also, the place of usual residence obtained an equality rate quite high: about 95 per cent of all register pairs compared had the exact same information.

As for the socioeconomic variables, the results are less homogeneous. We identify three situations:

- High equality rates for certain variables on all sources with available information; e.g.: status in 
employment with about 86 per cent of census correspondence via social security (ISS) and 93 per cent via private employment (QP);

- Equality rates with large variation by source: variables like profession, industry and current activity status; in this last one, about 92 per cent of correspondence via public retirement (CGA), while, considering the unemployment data (IEFP), this value decreases to 42 per cent;

- Equality rates estimated from comparison with a single source: from 50 per cent correspondence in the number of persons working in the enterprise (or hours usually worked) via private employment (QP) to more than 80 per cent on school attendance via students register (EDUC).

To support the census - administrative datasets comparison results, we decided to use the results from the 2011 Census PES quality indicator, ICG. Surprisingly, the estimated equality rates and the ICG values are very close to most selected variables (even though, to some variables, concepts are close, but don't exactly match). This fact supports the results obtained from the general comparison exercise and increases the credibility of using administrative information for census purposes.

Finally, to have an additional indicator to validate the obtained results, we also did the comparison 2011 Census - 2011 first quarter LFS ${ }^{2}$ microdata. The LFS sample size was 39884 individuals. For this exercise, it was necessary to apply a match-key (sex/name/date of birth/marital status/municipality of usual residence) with census records. We obtained 17732 pairs of records to compare with 2011 Census microdata (6995 aged 15 years and over).

Table 4 shows corresponding comparison results, census microdata vs. administrative information and census microdata vs. LFS microdata, on 8 labour force and educational variables. For this purpose, we use the highest equality rate comparison results from Table 3 , regarding census microdata vs. administrative information, whenever several administrative sources were available for a target variable.

Except for educational attainment, equality rates values from both comparisons, for selected variables, are similar. We consider that these results increase the overall consistency of the comparison exercise be-

\footnotetext{
${ }^{2}$ The Portuguese LFS, which is conducted nationwide, is a sample survey providing quarterly results (recently monthly). Back in 2011, it collected labour market information for approximately 40,000 individuals.
}

Table 4

2011 Census microdata and LFS comparison results

\begin{tabular}{lccc}
\hline Variables & $\begin{array}{c}\text { Equality } \\
\text { census-LFS } \\
(\%)\end{array}$ & $\begin{array}{c}\text { Equality Census - } \\
\text { administrative } \\
\text { records by selected } \\
\text { administrative } \\
\text { data source (\%) }\end{array}$ \\
\hline Labour force status & 84.3 & 81.2 & ISS \\
Occupation & 67.8 & 61.9 & QP \\
Industry & 77.6 & 74.1 & QP \\
Status in employment & 86.5 & 93.0 & QP \\
Number of persons working & 60.6 & 54.4 & QP \\
in the enterprise & 72.6 & 56.8 & QP \\
Hours usually worked & 80.2 & 59.5 & QP \\
Educational attainment & 86.5 & 87.4 & EDUC \\
School attendance & & &
\end{tabular}

tween the 2011 Census microdata and the administrative records.

At last, a final note on coverage issues. From Table 3 , it is obvious that some variables are not fully covered by the Portuguese administrative data available for the Feasibility Study of the 2021 Census. In fact, we know, from initial diagnostic information needs, that some core topics for population and housing census (e.g. variables related with household or education) are not fully or even partially covered by Portuguese administrative data. That is not an issue for the current exercise and neither are inconsistencies between sources (a set of rules has been prepared for that matter).

\section{Conclusions}

The evaluation of administrative data quality for statistical purposes can be a huge task. One step in this evaluation process is - after dealing with concepts, classifications, timeliness, processing and data treatment, data linkage and matching and other issues - verify if (despite cover issues) the information that we get from administrative data sources is what we need for census statistics and, more importantly, if it is valid and precise.

It is common sense that the compromise between what we have and what we need is difficult to achieve, particularly when the process involves resources that we do not detain or control, like administrative datasets. In this particular task, many countries that face the transition on the census model from traditional to register-based models, have the same problems of Portugal. For Statistics Portugal, this simple comparison exercise is part of a complex project which is a work in progress and should continue beyond the 2021 Census. 
We consider that the results can be a base for discussion on the purpose of administrative data usage to replace or to be used in addition to census data collection. At this time, we point out some conclusions/reflections on the obtained results:

- Results show an huge consistency between administrative data and 2011 Census microdata;

- We compared administrative data individuals records to seven 2011 Census demographic variables (all used in the match-key exercise). Those equality rates are very high (90 per cent of the compared pairs of records' information is exactly the same);

- We also compared labour force related and educational characteristics - from eight selected 2011 Census variables, we obtained more than 80 per cent of equality for some labour market variables;

- When comparing administrative data with 2011 Census microdata, private employment register (QP) was the most consistent source of information - with, globally, the highest equality rates across the set of available variables;

- Comparability indicators show inequalities only based in unequal values (the differences are not caused by impossible data conversion or miss- ing description); so, we consider that, although there's an obvious under coverage issue, administrative data can be use for add or replace information collected by census;

- Time lags between datasets and some conceptual issues could explain differences on comparison results; also, data sources holders are being contacted for new data flows and we believe that some of the issues that cause inequalities can be solved with more recent incomes;

- The reliability of using administrative data for statistical purposes was confirmed by using additional quality information criteria from the 2011 Census PES and the 2011 Census vs. 2011 LFS comparison results;

- For future work, cross comparison and hierarchical rules between sources of administrative information is being studied.

\section{References}

[1] Instituto Nacional de Estatística. Inquérito de Qualidade dos Censos 2011 - Metodologia e resultados, Instituto Nacional de Estatística, INE I.P. Ed., Lisbon, 2013. 